\title{
ARQUIVOS SECRETOS ECLESIÁSTICOS EM SALVADOR
}

\section{ARCHIVOS SECRETOS ECLESIÁSTICOS EN SALVADOR DE BAHÍA}

\author{
Ana Aparecida Gonzaga da Silva - cidaleah@yahoo.com.br \\ Arquivista pelo Instituto de Ciência da Informação da UFBA \\ Jussara Borges - jussarab@ufba.br \\ Doutoranda em Comunicação e Cultura Contemporâneas (Facom/UFBA). \\ Professora Assistente (ICl/UFBA)
}

\begin{abstract}
Resumo
O estudo investiga os critérios empregados por arquivos de ordens religiosas e pelo Arquivo da Cúria de Salvador para identificar o teor secreto de seus documentos. Consideram-se as relações históricas entre a Igreja Católica e o poder civil para compreender o porquê de muitos documentos depositados nos arquivos eclesiásticos brasileiros serem identificados como de interesse público e social pela lei nacional. $\mathrm{O}$ trabalho também destaca as disposições normativas existentes nas legislações civil e canônica relacionadas aos arquivos secretos. Apresenta ainda uma breve discussão sobre a questão do acesso e sigilo da informação, bem como sobre o direito à informação. Quanto aos procedimentos de pesquisa, utilizou-se o sítio eletrônico da Arquidiocese de Salvador na seleção das ordens masculinas e femininas estudadas; em seguida, foi aplicada entrevista com questões semi-estruturadas com a finalidade de coletar dados para os resultados empíricos desta pesquisa. Conclui-se que não existem critérios explícitos para a classificação dos documentos considerados secretos nos arquivos eclesiásticos católicos de Salvador, o que leva à utilização de critérios aleatórios e que seus responsáveis não demonstraram possuir domínio do significado de documentos secretos, já que entram em contradição em suas afirmações.
\end{abstract}

\section{Palavras-chave}

Arquivos eclesiásticos. Arquivo secreto. Direito à informação.

\section{INTRODUÇÃO}

A Igreja conseguiu, ao longo de sua história, arquivar um volume respeitável de documentos considerados históricos para a sociedade. Tais registros se encontram resguardados em Arquivos Eclesiásticos. Nesses espaços, não se encontram somente preservadas informações que relatam a memória da Igreja enquanto instituição, mas também há conservadas passagens da vida do povo brasileiro. Neste sentido, os arquivos privados eclesiásticos são considerados um bem cultural da Igreja e, ao mesmo tempo, de interesse público e social, especialmente no que toca à pesquisa científica. 
Portanto, estes arquivos, apesar de serem dotados de caráter privado, têm documentação classificada como de interesse público e social, e, desta forma, são patrimônio cultural da nação. Contudo, a classificação de um arquivo privado como de interesse público e social não assegura o direito ao acesso a esse arquivo, pois a legislação delega aos seus detentores a decisão de liberá-los à pesquisa.

Se, por um lado, discussões sobre acesso e sigilo da informação pública, bem como sobre uma política de informação para o Brasil, emergiram e evoluíram com a redemocratização do país - refletindo-se na própria Constituição e em leis específicas -, o mesmo não ocorreu com relação aos arquivos privados. Não são amplamente conhecidos os critérios de acessibilidade documental para os pesquisadores nos arquivos eclesiásticos nem como é definida a classificação do que é secreto. É possível que o acesso à documentação esteja pautado na legislação civil e principalmente na eclesial, mas também pode ser decorrência de decisões locais a despeito da legislação, o que pode representar um entrave para a pesquisa científica. Logo, este estudo coloca em questão os critérios empregados pela Igreja Católica em Salvador para identificar o teor secreto dos seus documentos e se esses encontram respaldo nas legislações civil e canônica.

Como afirma Santos (2005), há carência em criar políticas nesses espaços que sistematizem seus métodos e os tornem transparentes. A existência de uma definição que possa se transformar numa ferramenta de comunicação com a sociedade civil deve ser discutida na área arquivística, visando a incorporar esses arquivos no contexto e universo arquivístico atual.

Também é escassa a literatura sobre arquivos eclesiásticos, especialmente no que diz respeito às categorias de acesso a tais documentos. Santos (2005) afirma que houve poucas pesquisas referentes à análise de fontes documentais produzidas pela Igreja nos últimos anos. Apesar dessa deficiência na área, os poucos estudos que existem conseguiram recompor informações relativas a fenômenos sociais, políticos e econômicos.

Para Jardim (1999a), a partir dos anos 1990 o tema da acessibilidade contou com novas abordagens em arquivos públicos; porém, no que se refere ao acesso a arquivos privados, esta tendência não se manifestou, principalmente quando a abordagem visa aos arquivos secretos de instituições privadas. Desta forma, a escolha desse tema deve-se à necessidade de conhecer como, para quê e quem desenvolve os critérios de identificação documental para o arquivo secreto eclesiástico.

\section{PROCEDIMENTOS METODOLÓGICOS}

Os procedimentos metodológicos envolvem a identificação, o reconhecimento e a compreensão do caráter eclesial privado dos arquivos da Igreja; bem como a confrontação do acesso às informações nestas instituições com o direito à informação. Foi utilizada a abordagem indutiva, 
pois se trata de um estudo no universo dos arquivos eclesiásticos de Salvador, procurando verificar a possibilidade de generalização dos resultados constatados neste estudo.

Utilizou-se, para este estudo, o caráter descritivo; e, como método, a pesquisa bibliográfica e documental - nas legislações civil e canônica - e a pesquisa de campo em cinco ordens religiosas e no Arquivo da Cúria Metropolitana de Salvador. Segundo Costa (2003), dentro da estrutura da lgreja, destaca-se o papel das ordens religiosas, pois foram grandes colaboradoras no projeto português de colonização ao desempenhar a função de manutenção do culto e conversão dos indígenas.

A seleção das ordens deu-se a partir da relação de ordens religiosas masculinas e femininas disponibilizadas pelo sítio eletrônico da Arquidiocese de Salvador (2002). Foram selecionadas para esta pesquisa todas as ordens que possuem arquivos em Salvador. Portanto, as entidades que forneceram dados para esta pesquisa, a partir de entrevistas com os responsáveis pelos respectivos arquivos, são as apresentadas no Quadro 1.

\begin{tabular}{|l|l|}
\hline \multicolumn{1}{|c|}{ ARQUIVOS ECLESIÁSTICOS } & \multicolumn{1}{c|}{$\begin{array}{c}\text { ENTIDADES CUSTODIADORAS DE } \\
\text { ARQUIVOS EM SALVADOR }\end{array}$} \\
\hline Arquivo da Igreja e Mosteiro de São Bento & Ordem de São Bento (Beneditinos) \\
\hline Arquivo Histórico Nossa Senhora da Piedade & Ordem dos Frades Menores (Capuchinhos) \\
\hline $\begin{array}{l}\text { Arquivo da Igreja e Convento de São } \\
\text { Francisco }\end{array}$ & Ordem dos Frades Menores (Observantes) \\
\hline $\begin{array}{l}\text { Arquivo do Mosteiro de Nossa Senhora da } \\
\text { Conceição }\end{array}$ & $\begin{array}{l}\text { Ordem da Imaculada Conceição } \\
\text { (Concepcionistas) }\end{array}$ \\
\hline $\begin{array}{l}\text { Arquivo do Convento Nossa Senhora das } \\
\text { Mercês }\end{array}$ & $\begin{array}{l}\text { Ordem de Nossa Senhora de Santa Úrsula } \\
\text { (Ursulinas) }\end{array}$ \\
\hline $\begin{array}{l}\text { Arquivo do Convento Sagrado Coração de } \\
\text { Jesus e Nossa Senhora da Soledade }\end{array}$ & $\begin{array}{l}\text { Ordem de Nossa Senhora de Santa Úrsula } \\
\text { (Ursulinas) }\end{array}$ \\
\hline Arquivo da Cúria Metropolitana de Salvador & Arquidiocese de São Salvador da Bahia \\
\hline
\end{tabular}

Quadro 1: Arquivos eclesiásticos e suas entidades custodiadoras em Salvador.

Fonte: Pesquisa das autoras.

Foi entrevistado também o responsável pelo Arquivo da Cúria Metropolitana de Salvador por ser a maior entidade do gênero na Bahia, com o direito de emanar normas quanto ao acesso nos demais arquivos eclesiásticos de sua jurisdição. Para a coleta de dados, o instrumento utilizado foi um roteiro de entrevista, através da técnica de entrevista semiestruturada. 


\section{ARQUIVOS ECLESIÁSTICOS}

Os arquivos eclesiásticos guardam fontes primárias religiosas e cíveis que auxiliam no processo de reconstrução histórica. A significação de fontes de caráter eclesiástico é destacada pela Fundação Histórica Tavera (2000) como um complemento importante às fontes documentais de origem civil, ainda que seja um patrimônio praticamente desconhecido no Brasil, além de que os fundos documentais eclesiásticos nacionais representam quase um terço do total de todos os arquivos brasileiros. Segundo Hayes (2008?), entende-se como arquivos eclesiásticos ou religiosos:

[...] uma coleção de documentos, registros, e memoriais, relativos à origem, fundação, o crescimento, a história, os direitos, privilégios, e constituições de uma diocese, paróquia, mosteiro, ou comunidade religiosa sob a jurisdição da lgreja, o termo também é aplicado a um local ou depósito em que tais registros e documentos são mantidos.

A existência de arquivos eclesiásticos, garante Abreu (2000), surgiu a partir do século IV, a partir do qual se encontram testemunhos sobre a conservação do patrimônio dos arquivos. Os arquivos eclesiásticos constituíram-se com o primeiro grande arquivo no pontificado do Papa Dâmaso (366-384), com sede na Basílica de São Lourenço. No ano de 648, o acervo foi transferido para a Basílica de São João de Latrão. A exemplo de outras entidades eclesiásticas, os mosteiros e as universidades do século XIII, como as de Bolonha e de Paris, pertencentes às escolas episcopais, também mantiveram arquivos (ABREU, 2000).

A existência de fontes documentais de origem pública em arquivos eclesiásticos remonta ao período do reconhecimento do catolicismo como religião oficial por parte do Império Romano, saindo a Igreja Católica da clandestinidade com a criação de um estatuto jurídico próprio para a religião. Santos (2005) crê que a prática de depositar documentos de natureza civil em entidades religiosas católicas se devia ao alto nível de organização da mesma naquela época. A partir de então é atribuído lentamente o caráter de fé pública aos atos privados da lgreja; consequentemente, os arquivos da Igreja também passam a responder como instrumento de tutela de direitos e do ordenamento civil e eclesiástico (SANTOS, 2005).

A partir da Constituição Sollicitudo pastorallis, de 1565, surge uma regulamentação para o funcionamento dos arquivos pontifícios, além da criação do ofício de Prefeito dos Arquivos e da recomendação de criação dos arquivos públicos e gerais em todas as catedrais, mosteiros e abadias do Estado Eclesiástico. Considera-se, a partir de então, o surgimento das práticas arquivísticas mais normalizadas e frequentemente aprimoradas em arquivos eclesiásticos (ABREU, 2000). No ano de 1611, sob o papado de Paulo V, cria-se o Arquivo Secreto do Vaticano, que também é considerado o arquivo geral da Igreja Católica (DOMINUS VOBISCUM, 2007?). Em 1727, no pontificado de Bento XIII, com a constituição Maxima Vigilantia, cria-se o tratado sobre arquivística que embasou a legislação eclesiástica atual (ABIB, 1999). 
No Brasil, as primeiras normas que deram iniciação à administração dos arquivos eclesiásticos foram As Constituições Primeiras do Arcebispado da Bahia e o seu Regimento do Auditório, de 1707, que estavam em acordo com o Concílio de Trento e vigoraram até a promulgação do Código de Direito Canônico (CDC) de 1917 (ABIB, 1999).

Atualmente, de acordo com o CDC (IGREJA CATÓLICA, 1983), os arquivos eclesiásticos encontram-se organizados em: 1) arquivo diocesano, que, por sua vez, subdivide-se em corrente (cân. 486), secreto (cân. 489) e histórico (cân. 491); 2) arquivos colegiados (cân. 491 § 1); 3) arquivos paroquiais (cân. $491 \S 1$ ); 4) arquivos de fundações pias (cân. $1306 \S 2$ ); 5) arquivos das Igrejas catedrais (cân. $491 \S 1$ ); e 6) arquivos de outras igrejas dos territórios (cân. $491 \S 1$ ). De acordo com Santos (2005), entre as seis tipologias encontradas no Código de 1983, duas são as mais importantes: o arquivo diocesano ou episcopal (que possui um arquivo secreto e dois arquivos não secretos) e o arquivo paroquial. Estas duas tipologias são consideradas as mais importantes em razão de seus arquivos serem mencionados como os mais antigos e estarem ligados a instituições eclesiásticas maiores, que se distribuem em três serviços ministeriais: o ministério diaconal, o ministério episcopal e o ministério presbiterial. As duas últimas respondem aos arquivos diocesano e paroquial, que, por sua vez, estão sujeitos, respectivamente, à tutela do bispo diocesano e do presbítero ou pároco.

\subsection{Arquivos eclesiásticos como bens culturais e fontes de informação}

O Código de Direito Canônico de 1917 constitui um marco à iniciativa de regulamentação e valorização dos arquivos na história da Igreja. Porém, foi durante o pontificado de João Paulo II (1978-2005) que os arquivos ganham valor de bem cultural e passam a constituir um importante componente do universo cultural da Igreja Católica.

Para Santos (2005), a partir de João Paulo II, a Igreja passou a adotar uma política de abertura dos seus arquivos, utilizando seus bens, dentre eles as artes, as bibliotecas, os arquivos e os meios de comunicação social para transmitir ao mundo a cultura cristã. Para administrar o patrimônio cultural da Igreja, João Paulo II criou a Comissão Pontifícia para a Conservação do Patrimônio Artístico e Histórico, em 28 de junho de 1988, através do decreto Pastor Bonus. Com a extinção dessa Comissão, criou-se, em 25 de março de 1993, a Comissão Pontifícia para os Bens Culturais da Igreja com o Motu Próprio "Inde a Pontificatus Nostri Initio". Essa Comissão tem como funções básicas: presidir a tutela do patrimônio histórico e artístico de toda a Igreja; colaborar na conservação do patrimônio das Igrejas particulares e nos respectivos organismos episcopais; promover a sensibilização cada vez maior nas Igrejas sobre estes bens, de acordo com as Congregações para a Educação Católica e para o Culto Divino e a Disciplina dos Sacramentos (COMISSÃO PONTIFÍCIA PARA OS BENS CULTURAIS DA IGREJA, 2008?). 
A Comissão criou, ao longo de sua existência, alguns documentos que dizem respeito ao patrimônio cultural da Igreja (obras de arte, documentos históricos e aqueles que se conservam em museus, bibliotecas e arquivos); dentre eles, destacam-se, para esta pesquisa, as cartas circulares: "A função Pastoral do Arquivo", de 02 de fevereiro de 1997, e "Os bens culturais dos institutos religiosos", de 10 de abril de 1994.

A Comissão propõe concentrar os documentos em algumas sedes adequadas à pesquisa e os tornar acessíveis à distância, se possível com os processos de reprodução fotográfica e digital, pois tais atitudes proporcionariam o intercâmbio de informações entre os institutos, além da criação de um banco de dados comum. Ambos os documentos, no entanto, servem apenas como sugestão da Cúria Romana com vista a uma adequação e padronização dos diversos arquivos eclesiásticos do mundo.

A Igreja, no Brasil, ainda não criou uma política arquivística que regulamente e agregue os seus arquivos com base nessas orientações. A Fundação Histórica Tavera (2000) afirma que não há nos arquivos eclesiásticos do Brasil qualquer ação, em nível nacional ou estadual, que se ocupe da coordenação de projetos voltados ao seu patrimônio documental, nem a inter-relação entre os arquivos eclesiásticos, além de que, atuações relacionadas a essa preocupação geralmente se reduzem a atos isolados, como convênios estabelecidos com centros universitários.

Como instituição que possui caráter privado, a Igreja tem o direito à propriedade plena para desfrutar dos bens, móveis ou imóveis, que adquiriu, mas também deve apreciar e respeitar as legislações vigentes sobre os arquivos considerados como de interesse público e social nos países em que se encontra o seu patrimônio documental. Abib (1999, p. 3) afirma que as Igrejas da América do Sul possuem patrimônios notáveis, considerando que são, na sua maioria, os "principais vestígios da história nas respectivas nações".

A Lei n 8.159 (BRASIL, 1991), que dispõe sobre a política nacional dos arquivos públicos e privados, identifica os registros civis de arquivos de entidades religiosas produzidos anteriormente à vigência do Código Civil como de interesse público e social. Estes registros civis se encontram guardados nos arquivos eclesiásticos diocesanos: são, em geral, registros de batismos, de óbito e de matrimônios, feitos em paróquias até a promulgação do Decreto 119-A, de 7 de janeiro de 1890 (BRASIL, 1890).

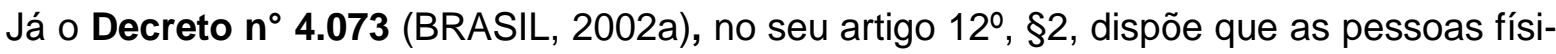
cas e jurídicas de direito privado, detentoras de arquivos, podem integrar o Sistema Nacional de Arquivos (SINAR) mediante acordo ou ajuste com o órgão central. Portanto, a Igreja, no Brasil, como uma instituição de personalidade jurídica de direito privado, poderia buscar essa integração, visando a estabelecer políticas arquivísticas adequadas aos arquivos eclesiásticos. A Fundação Histórica Tavera (2000) afirma que a Igreja poderia manter sua independência administrativa e 
jurídica, onde a integração ocasionaria a coordenação de ações; sugere ainda que tal acordo aconteça a cargo da Conferência Nacional dos Bispos do Brasil (CNBB).

\section{ARQUIVOS SECRETOS}

Até o final do século XVIII, os arquivos secretos pertenciam ao Estado e existiam para servir à administração monárquica. Com a criação dos arquivos nacionais a partir da Revolução Francesa, os arquivos passaram a servir ao cidadão e aos antigos arquivos secretos do Estado foi dado um caráter público após período determinado em lei, sendo reconhecido o direito legal à consulta pública por parte do cidadão após a Segunda Guerra. Costa (1998) afirma que com a Revolução Francesa é dado aos arquivos um caráter nacional, além da substituição do segredo de Estado pelo princípio da publicidade. Mesmo assim, a França e outros países, como a Inglaterra e a Itália, impunham muitas restrições e fixavam prazos longos para a abertura dos documentos ao historiador e ao público em geral (COSTA, 1998).

A Igreja refere-se ao arquivo secreto no CDC, que menciona a existência de um arquivo, que constitui uma parte do arquivo diocesano, que será mantido separado dos outros arquivos em função dos documentos possuírem caráter sigiloso. Na legislação brasileira vigente, existem disposições relacionadas à documentação pública de caráter sigiloso, que possui como categoria o grau de documentos secretos. A lei de arquivos reservou ao capítulo $\mathrm{V}$ questões voltadas ao acesso e ao sigilo dos documentos. Vianna (1999, p. 90) ressalta que esses arquivos:

[...] descrevem o que é importante para qualquer instituição, conhecendo ou escondendo fatos ou responsáveis, fatos esses, geralmente, de ordem ética e que podem comprometer a boa imagem de um país ou de uma instituição. Os arquivos, em geral muito úteis para a reconstituição do poder dos segredos em determinadas épocas, podem, entretanto, ser transformados em cinzas como os arquivos de Auschwitz, ou podem desaparecer como aconteceu com o massacre de negros nos Estados Unidos na década de XX (sic), ou, simplesmente, sumir como tantos arquivos da história recente e passada do Brasil.

\subsection{Legislação Canônica}

Pela definição do Arquivo Geral do Vaticano, que também possui o nome de Arquivo Secreto, como um resquício linguístico do passado, entende-se que "secreto" vem do latim segregare, colocar à parte, porque antes o arquivo ficava junto à biblioteca - arquivo-biblioteca -, e se decidiu deixar uma parte para consultas do papa, explica o cardeal Jorge María Mejía, responsável pelo arquivo (GALÁN; MORA, 2003).

A Igreja é amparada juridicamente pelo Código de Direito Canônico (CDC), que é o instrumento que estabelece e regula normas para toda a lgreja. O CDC é o principal documento regula- 
dor da Igreja, baseado na herança jurídica da tradição cristã que tem por função garantir a ordem tanto na vida individual e social dos cristãos, como também nas atividades internas da instituição. Santos (2005, p. 68) afirma que o Código assegura ao arquivo um papel importante no processo de guarda, preservação e disseminação de informações referentes às atividades da Igreja. $\mathrm{O}$ arquivo é encarado no documento como um bem eclesiástico que preservará para a posteridade a materialização documental de sua evangelização; no entanto, existem algumas restrições à pesquisa em algumas tipologias documentais. Então, faz-se necessário esclarecer o porquê do teor secreto dos documentos e principalmente como é realizada tal classificação. Os cânones 489 e 490 asseguram a esse respeito que:

Cân. $489 \S 1$. Haja também na cúria diocesana um arquivo secreto, ou pelo menos haja no arquivo comum um armário ou cofre, inteiramente fechado à chave que não possa ser removido do lugar; nele sejam guardados com a máxima cautela os documentos que devem ser conservados em segredo; § 2. Cada ano sejam destruídos os documentos das causas criminais em matéria de costumes, cujos réus tenham falecido, ou que já tenham sido concluídas há dez anos, com sentença condenatória, conservando-se breve resumo do fato como texto da sentença definitiva.

Cân. 490 § 1. Somente o Bispo tenha a chave do arquivo secreto; § 2. Estando vacante a sé, o arquivo ou armário secreto não seja aberto, a não ser pelo próprio Administrador diocesano em caso de verdadeira necessidade; § 3. Não se retirem documentos do arquivo ou armário secreto. Documentos do arquivo (ou armário) secreto não serão emprestados em hipótese alguma (IGREJA CATÓLICA, 1983, p. 38).

Percebe-se que, uma vez classificado como secreto, jamais se terá acesso ao documento, já que não há previsão de prescrição para o teor secreto e avaliação de seu valor histórico: ou o documento permanece inacessível no arquivo secreto ou é destruído. Sob o critério de que sejam guardados em segredo estão os documentos que contenham informações sobre: as dispensas de impedimentos ocultos*, concedidas no foro interno não sacramental (cân. 1082); os matrimônios celebrados secretamente (cân. 1133); os registros de repreensões (cân. 1339 § 3); os autos de investigação e os decretos do Ordinário com os quais se inicia ou se conclui uma investigação, bem como tudo que precede à investigação (cân. 1719). São poucos os tipos documentais considerados secretos e aos quais o público não pode ter acesso.

Quanto aos instrumentos de pesquisa, o novo CDC exige tanto dos arquivos diocesanos quanto dos paroquiais a elaboração de catálogo com um resumo de cada item documental (cân. $486 \S 3$ ), mas não se refere aos instrumentos de pesquisa para documentos do arquivo secreto, ao contrário do CDC de 1917, que exigia a sua inventariação (cân. 379 § 2). Cabe ao bispo o de-

\footnotetext{
* O significado remete à dispensa como resultado do processo de uma pessoa para contrair validade ao matrimônio, ou ainda proveniente do voto público perpétuo de castidade num instituto religioso de direito pontifício. Tal dispensa é considerada oculta quando aprovada no foro interno do Tribunal eclesiástico. (IGREJA CATÓLICA, 1983).
} 
ver de fazer com que os outros arquivos eclesiásticos façam inventários ou catálogos de seus registros (cân. 491 § 1) (SANTOS, 2005). Quanto ao acesso, o novo CDC informa:

[...] para ter acesso ao arquivo diocesano é necessária a licença do bispo ou do moderador da cúria e do chanceler (cân. 487 § 1); os que trabalham no arquivo curial devem permitir o acesso aos documentos arquivísticos aos que legitimamente os solicitarem (cân. $2406 \S 1$ );

os documentos arquivísticos não conservados no fundo diocesano também podem ser consultados, desde que sejam observadas as normas estabelecidas pelo bispo (cân. 491 § 3) (IGREJA CATÓLICA, 1983, p. 24).

Desta forma, observa-se que os arquivos eclesiásticos diocesanos sofrem uma política de restrição quando se trata de acesso, e de maneira geral é visto que outros arquivos de entidades religiosas também passam pela mesma ressalva. Apesar da política de abertura dos arquivos sob a guarda da Igreja, principalmente a partir do pontificado de João Paulo II, a figura do órgão é ainda de natureza privada e de gestão administrativa eclesiástica, sendo franqueado o acesso aos documentos de acordo com a decisão do responsável.

Esse regramento não se fez acompanhar no âmbito nacional. Muitas vezes, talvez por falta de formação adequada, os responsáveis pelos arquivos confundem a grande maioria de documentos não sigilosos com aqueles poucos que efetivamente o são (ABIB, 1999). Além de que, na maioria dos arquivos eclesiásticos brasileiros não existem normas explícitas no que diz respeito ao acesso, reprodução e manuseio de seus documentos. Em arquivos em que há regulamentos, é adequado que sejam tornados públicos e que as normas sejam harmonizadas com as do Estado brasileiro.

O CDC evidencia que cada diocese e cada instituto religioso é responsável pela sua administração, bem como pela regulamentação dos seus arquivos. Santos (2005) destaca que as conferências episcopais e de superiores maiores dos institutos religiosos não possuem um poder regulamentar ou coercivo, mas podem, e devem, sugerir orientações e ter uma missão de aconselhamento na definição da política de gestão de arquivos, tal como sugere com a Comissão Pontifícia dos Bens Culturais.

Por fim, é importante ressaltar que a Santa Sé dispõe de acordos internacionais, multilaterais e bilaterais com diversos países sobre os bens culturais da lgreja. Dentre estes acordos, destaca-se o do patrimônio documental arquivístico. O Brasil possui somente um acordo bilateral assinado na cidade do Vaticano pelo Ministério das Relações Exteriores com a Santa Sé, em 13 de novembro de 2008. São consideradas no acordo as relações históricas existentes entre a Igreja Católica e o Brasil, assim como suas respectivas responsabilidades a serviço da sociedade brasileira. O acordo ainda reafirma, no artigo 3, "a personalidade jurídica da Igreja Católica em conformidade com o direito canônico, desde que não contrarie o sistema constitucional e as leis brasileiras" (BRASIL, 2008). Entretanto, apesar desta medida, tal acordo ainda não entrou em vigor. 


\subsection{Legislação Civil}

A Lei $n^{\circ} 8.159$ estabelece parâmetros para o sigilo dos documentos que possam pôr em risco a segurança do Estado e a privacidade do cidadão, e ainda estabelece que os documentos sigilosos, de valor probatório, informativo e histórico, de guarda permanente, não podem ser destruídos (BRASIL, 1991). Estes parâmetros são definidos nos artigos $22^{\circ}$ a 24ํำ do capítulo $V$ da Lei de Arquivos, que trata das questões de acesso e sigilo à informação, e nos artigos $4^{\circ}, 5^{\circ}$ e $6^{\circ}$ do capítulo I da referida lei.

Existem ainda dois decretos que prevêem ações para regulamentar a questão do sigilo: o Decreto $n^{\circ}$ 4.553, de 27 de dezembro de 2002 (BRASIL, 2002b), e o Decreto $n^{\circ} 5.301$, de 9 de dezembro de 2004 (BRASIL, 2004). O Decreto $n^{\circ} 4.553$ revoga os três anteriores: o de $n^{\circ} 4.497$, de 4 de dezembro de 2002, o de $n^{\circ} 2.910$, de 29 de dezembro de 1998, e o de $n^{\circ} 2.134$, de 24 de janeiro de 1997, este último revogou o de $n^{\circ}$ 79.099, de 6 de janeiro de 1977, conhecido como "Decreto Geisel, extremamente autoritário e que constituía parte do entulho do regime militar, a ser eliminado da vida jurídica do país" (COSTA, 2003, p. 5).

O Decreto $n^{\circ} 4.553$, que dispõe sobre a salvaguarda de dados, informações, documentos e materiais sigilosos de interesse da segurança da sociedade e do Estado, no seu artigo $2^{\circ}$, define que são documentos sigilosos:

[...] dados ou informações cujo conhecimento irrestrito ou divulgação possa acarretar qualquer risco à segurança da sociedade e do Estado, bem como aqueles necessários ao resguardo da inviolabilidade da intimidade da vida privada, da honra e da imagem das pessoas.

Parágrafo único. O acesso a dados ou informações sigilosos é restrito e condicionado à necessidade de conhecer (BRASIL, 2002b).

O decreto define ainda, em seu artigo $5^{\circ}, \S 2$, que os dados sigilosos serão classificados em ultra-secretos, secretos, confidenciais e reservados, em razão do seu teor ou dos seus elementos intrínsecos. Finalmente, a definição dos documentos de teor secreto é utilizada como tal para:

[...] os dados ou informações referentes a sistemas, instalações, programas, projetos, planos ou operações de interesse da defesa nacional, a assuntos diplomáticos e de inteligência e a planos ou detalhes, programas ou instalações estratégicos, cujo conhecimento não-autorizado possa acarretar dano grave à segurança da sociedade e do Estado (BRASIL, 2002).

No seu artigo 6ํㅡㄹ diz que a classificação no grau secreto é de competência das seguintes autoridades: as que exerçam funções de direção, comando, chefia ou assessoramento, de acordo com regulamentação específica de cada órgão ou entidade da Administração Pública Federal (BRASIL, 2002b). Quanto aos prazos de duração da classificação a que se refere este decreto 
(artigo $\left.7^{\circ}\right)$, vigoram a partir da data de produção do dado ou informação secreta até o máximo de vinte anos.

Costa (2003) afirma que o Decreto n 4.553 altera a Lei $n=8.159$, tornando-se inconstitucional, e amplia os prazos de restrição ao acesso, contrariando as novas tendências nos quais predomina a diminuição de prazos relativos ao segredo de Estado. O Decreto № 4.553, no seu artigo 35, cria também a Comissão Permanente de Avaliação de Documentos Sigilosos (CPADS), resultado da "mistura" das comissões previstas nos Decretos n 2.134/1997 (Comissão Permanente de Acesso) e no 4.073/2002a (Comissão Permanente de Avaliação de Documentos) (RODRIGUES; HOTT, 2007).

Já o Decreto n 5.301 (BRASIL, 2004) regulamenta o disposto na Medida Provisória nº 228 (convertida na Lei $\mathrm{n}^{\circ}$ 11.111), de 9 de dezembro de 2004, que dispõe sobre a ressalva prevista na parte final do disposto no inciso XXXIII do artigo $5^{\circ}$ da Constituição (BRASIL, 1988). O decreto estabelece quais as categorias de sigilo, os prazos de abertura dos documentos e as autoridades hierarquicamente responsáveis, além de instituir no âmbito da Casa Civil a Comissão de Averiguação e Análise de Informações Sigilosas (artigo 4ํ). No seu artigo 3ํㅡ, estabelece que seja documento público aquele "pertencente à administração pública e às entidades privadas prestadoras de serviços públicos, fixada materialmente e disposta de modo que se possa utilizar para informação, consulta, estudo ou prova".

De acordo com a Lei 11.111, de 5 de maio de 2005, que ratifica o Decreto $n^{\circ} 5.301$, a Comissão de Averiguação e Análise de Informações Sigilosas poderá manter restrição ao acesso do documento pelo tempo que determinar. A lei estabelece a qualquer pessoa o direito de manifestação na referida Comissão para que reveja a decisão de ressalva ao acesso de documento público classificado no mais alto grau de sigilo (BRASIL, 2005). Entretanto, no seu artigo 6ㅇ $§ 4$, dá à Comissão a decisão final quanto à permanência da ressalva ao acesso do documento, pelo tempo que estipular.

Está no Congresso Nacional um projeto de lei elaborado pelo Governo que regula o acesso a informações previsto no inciso XXXIII do artigo 5ํㅡ, no inciso II do $\S 3$ do artigo $37^{\circ}$ e no $\S$ 2 do artigo 216 da Constituição, no âmbito da Administração Pública Federal. Tal projeto define informação sigilosa como "aquela submetida temporariamente à restrição de acesso público em razão de sua imprescindibilidade para a segurança da sociedade e do Estado" (RECONDO, 2008). Se o projeto de lei for aprovado, no seu artigo $39^{\circ}$ é citado que serão revogadas a Lei $n^{\circ}$ 11.111 e os artigos $22^{\circ}$ a $24^{\circ}$ da Lei $n^{\circ} 8.159$. O projeto de lei regula que o acesso às informações públicas será assegurado mediante: 
[...] criação do Serviço de Informações ao Cidadão - SIC, nos órgãos e entidades públicas, em local com condições apropriadas para: a) atender e orientar o público quanto ao acesso a informações; b) informar sobre a tramitação de documento nas suas respectivas unidades; c) protocolar documentos e requerimentos de acesso a informações; e realização de audiências ou consultas públicas, o incentivo à participação popular ou a outras formas de divulgação (BRASIL, 2009).

Apesar de estar em tramitação no Congresso - o que já representa um avanço para a questão do acesso e sigilo dos documentos públicos -, o projeto mantém um ponto criticado, pois determinadas informações poderão permanecer reservadas eternamente. Para coibir as autoridades a classificarem documentos indiscriminadamente com o mais alto grau de sigilo, a lei estabelecerá algumas restrições; por exemplo, o órgão que classificar o documento com o grau de ultrasecreto e secreto deverá esclarecer as razões a uma comissão coordenada pela Casa Civil, composta por Ministros de Estado ou autoridades com o mesmo direito (RECONDO, 2008).

O olhar panorâmico empreendido pela legislação civil nos permite observar que houve mais avanços que retrocessos quanto ao acesso à informação pública no Brasil. Em suma, a legislação regulamenta o acesso aos documentos públicos e presume que o sigilo deve ser tratado como uma exceção. Ainda assim, a legislação apresenta lacunas que permitem que alguns governos criem e se utilizem de muitas restrições de acesso aos documentos públicos.

Da mesma forma, é necessária a existência de uma política arquivística para os documentos eclesiásticos, traduzida em leis específicas e acordos que respeitem a natureza procedente da documentação eclesial, mas garantam o direito à informação. A vinculação da referida política às disposições canônicas e à legislação arquivística brasileira definiria qual a função dos instrumentos de restrição aos documentos eclesiásticos diante de patrimônio documental tão importante para a conjuntura cultural do Brasil.

\section{DIREITO À INFORMAÇÃO}

O direito à informação nasce a partir da Constituição da Suécia, de 1776, porém ganha reconhecimento na França a partir da Declaração de 1789, que afirmava a liberdade de opinião e a livre comunicação das ideias e opiniões. Posteriormente, encontra na Declaração Universal dos Direitos do Homem, de 1948, sua formulação mais precisa e transformadora, pois o acesso à informação se torna um direito democrático de todos os cidadãos e não mais uma exigência somente da pesquisa científica (COSTA, 1998).

Porém, até a primeira metade do século XX não se observam modificações significativas com relação a esta questão, mas é no período posterior à II Guerra Mundial que começam ações expressivas nesse sentido. Em 1966, a lei conhecida como Freedom of Information Act nos Estados Unidos se torna um marco na conquista do direito de acesso aos arquivos. A partir desta lei, 
diversos países criaram legislações semelhantes; apesar das particularidades encontradas em cada país, têm em comum o princípio do direito de acesso aos documentos dos arquivos públicos, salvo as exceções previstas em lei (FONSECA, 1999).

Ainda em acordo com Fonseca (1999), procura-se compreender o direito à informação como consequência da convergência entre a esfera pública e o direito à privacidade, sendo dever do Estado manter sob sigilo informações relativas à intimidade dos indivíduos. Devido a esta dualidade, segundo Costa (1998), assiste-se atualmente à redução do espaço público enquanto campo destinado ao debate político das grandes causas, mas também é observada a contínua expansão da esfera social e privada fazendo aumentar os direitos da sociedade e do indivíduo: "O espaço das liberdades públicas e o interesse pelo bem comum, retomados no século XVIII, começam a ser substituídos pelos interesses sociais dos grupos, classes, associações e partidos políticos, entre outros, próprios da sociedade moderna" (COSTA, 1998, p. 3).

Para Jardim (1999a) o acesso à informação encontra no direito à informação o seu regime jurídico. O acesso situa-se "não apenas como um direito civil, mas como um direito político e um direito social, compondo uma dimensão historicamente nova da cidadania". Afirma ainda que depois das recentes teorias democráticas do Estado, o regime jurídico da informação contraiu alterações que visam a conceber a relação entre Estado democrático e sociedade civil. A liberdade individual passa a ser apreciada no âmbito público e social; consequentemente, apontam-se e se debatem sobre ações que defendam o interesse da coletividade. Jardim (1999a, p. 3) admite ainda que

[...] o acesso jurídico à informação não se consolida sem o acesso intelectual à informação. $O$ acesso jurídico à informação pode garantir ao usuário o acesso físico a um estoque informacional materialmente acessível (um "arquivo" no subsolo de um organismo governamental, por exemplo) sem que seja possível o acesso intelectual dada à ausência de mecanismos de recuperação da informação. As experiências internacionais e, em especial o caso brasileiro, deixam claro que não se viabiliza o direito à informação governamental sem políticas públicas de informação.

Portanto, o termo "acesso" relaciona-se a um direito, mas também a um conjunto de medidas que o viabilizem (JARDIM, 1999b). Diante disto, o direito à informação trata-se também de um direito social, pois pressupõe a existência de serviços públicos responsáveis pelo atendimento ao cidadão; deste modo, tanto o Estado quanto a sociedade civil interagem na esfera pública (JARDIM, 1999b). O direito à informação faz, portanto, referência aos direitos civis, políticos e sociais, que, ao longo dos séculos, foram firmando-se no direito jurídico e, consequentemente, na legislação dos estados democráticos.

Contudo, estudos sobre o direito ao acesso em arquivos privados não evidenciam tendências de crescimento na área arquivística (JARDIM, 1999a). Possivelmente isso se deva ao reconhecimento desses arquivos como de caráter privado. Particularmente, dentro da estrutura da 
Igreja Católica, a Sé Apostólica possui personalidade jurídica equiparada às soberanias estrangeiras, com um corpo de normas estabelecido e voltado à proteção jurídica da Igreja e seu patrimônio.

Abib (1999) afirma que atualmente a Igreja investe muito mais na área social que na defesa do seu patrimônio cultural, pois a categoria que menos respondeu ao questionário da Fundação Histórica Tavera foi a eclesiástica. Assim, só poderá ser feito algo quando houver investimentos nos arquivos e quando houver uma política efetiva que englobe os arquivos eclesiásticos. Um exemplo a ser seguido pela Igreja trata-se do CPDOC da Fundação Getúlio Vargas que planeja formar um centro de referência em arquivos pessoais, possivelmente em parceria com o CONARQ, que cadastre e localize tais fundos em instituições públicas e privadas.

No caso da propriedade privada dos arquivos eclesiásticos, a temática do direito à informação possui um alcance previsto na legislação brasileira quanto ao seu papel social e de seu interesse público. Cabe ao Estado, deste modo, definir políticas de incentivo à pesquisa nestes arquivos que estimulem os seus proprietários a liberar o acesso aos seus documentos. Conclui-se este item com uma citação de Costa (1998, p. 11) em que afirma que "o pleno exercício da cidadania consistirá, exatamente, em garantir a transparência e a visibilidade dos arquivos, sem abrir mão do respeito à privacidade e à vida reservada dos indivíduos".

\section{RESULTADOS E DISCUSSÃO}

Nos arquivos eclesiásticos de Salvador, as principais tipologias documentais encontradas são: das relações com a Santa Sé ou Bispos (negociações diplomáticas, correspondências dos bispos); da relação espiritual (livros raros e regras do mosteiro); da administração (informações de finanças, dispensas de impedimentos ocultos, atas de investigação.); e da relação pessoal (registros de repreensões, batismo, óbito, casamento, informações pessoais).

A partir do testemunho dos responsáveis pelos arquivos pesquisados, quatro disseram que não existem documentos secretos nos acervos, mas pelo menos dois destes mencionaram documentos que o CDC considera secretos: dispensas de impedimentos ocultos e registros de repreensões. Demonstra-se que estes entrevistados desconhecem as questões referentes aos documentos secretos identificados pelo CDC de 1983. Além disso, embora três tenham registrado a existência de "dispensas de impedimentos ocultos", quando a entrevistadora apresentou uma listagem com tipos documentais, somente um demonstrou conhecimento da definição deste tipo de documento, que se refere aos processos administrativos da vida pessoal de cada religioso, ou sacerdote diocesano, ou ainda aos processos de dispensa aos impedimentos de matrimônio. Observou-se que um entrevistado, mesmo sendo responsável pelo arquivo, explanou não ter contato com a documentação, pois ela se encontra desorganizada. 
Há informações reservadas, relativas à vida íntima dos religiosos da ordem que não podem ser consideradas de interesse público e social, conforme explicitados pelo projeto de lei que regula o acesso às informações públicas, no seu artigo $26^{\circ} \S 1$, para as informações pessoais, que prevê um prazo de 100 (cem) anos de sigilo, a contar da data de sua produção. Entretanto, nos arquivos pesquisados não são identificadas datas de prescrição do sigilo para a documentação secreta relativa à vida intima dos religiosos. Portanto, pode haver documentação fora deste prazo de 100 anos que não poderia ser considerada secreta.

Há ainda documentos referentes a processos e trâmites administrativos da própria igreja. Quando se trata de documentos correntes, relativos a processos administrativos, não são liberados à consulta pública. No entanto, passado esse período, os documentos deveriam ser avaliados e liberados à consulta. Os documentos relativos à correspondência, finanças e negociação diplomática que, enquanto correntes, têm acesso restrito, obviamente, quando finalizado o período administrativo também poderiam servir à pesquisa.

Somente um arquivo possui documentos considerados secretos de acordo com a legislação civil, com material confidencial relativo às perseguições políticas sofridas por pessoas da instituição no período da ditadura. Isto decorre do fato da ordem em questão ter abrigado e defendido presos políticos. Quando se trata do acesso a tais documentos, estes são liberados à consulta dos envolvidos e familiares, bem como a pesquisas específicas.

Os documentos relativos às negociações diplomáticas referem-se às relações entre o governo do Vaticano com a igreja, seja esta representada pelas dioceses ou institutos de vida consagrada. Desta forma, os documentos diplomáticos existentes nos acervos não são aqueles referidos na legislação civil brasileira. Ressalta-se também que no Arquivo da Cúria de Salvador é reconhecida a existência de documentos secretos por parte do seu responsável; entretanto, tais documentos não estão no seu acervo, mas abrigados no setor jurídico da Arquidiocese, justamente por conter informações sigilosas.

Por outro lado, apesar de todos reconhecerem que são responsáveis por acervos com documentos históricos, dois dos entrevistados não consideram a maioria dos documentos abrigados em seu acervo como de interesse público e social. Infere-se que isso ocorra em função da expressão "interesse público", que leva ao entendimento de estes documentos serem de direito a toda sociedade, ou ainda ao entendimento que aquilo que é privado não deve ser liberado à consulta pública. Outra possibilidade é que estes entrevistados também desconheçam a legislação arquivística sobre os documentos considerados como de interesse público e social por parte do Estado. Entretanto, como afirma Costa (1998), é preciso criar uma nova mentalidade com relação à importância e à utilização das informações provenientes dos documentos de arquivos. Ora, o conflito entre o público e o privado sempre estará presente nestes locais; no entanto, o que deve 
ser levado em consideração é a sua dimensão histórica, característica básica que excede a sua natureza legal.

Os documentos eclesiásticos anteriores ao Código Civil constituem um conjunto de fontes relevantes para a história e o desenvolvimento científico nacional, conforme reconhecido com a Lei $n^{\circ}$ 8.159/1991. O Estado brasileiro necessita assegurar o acesso a tais informações através de contrapartida financeira e técnica para que a Igreja cumpra efetivamente seu dever de disponibilizar esse conjunto documental a partir de práticas arquivísticas transparentes. Demonstra-se por parte da Igreja uma disponibilidade para a abertura dos seus arquivos; no entanto, justifica a dificuldade em fazê-lo principalmente pela falta de recursos para administrar essa documentação.

Quanto aos critérios utilizados para classificar um documento como secreto, os dados levantados apontaram que nenhum dos arquivos estudados possui política para classificar um documento com o teor secreto, nem mesmo critérios explícitos para tal classificação. Deste modo, assim como a legislação brasileira não explicita como o classificador aplica uma classificação do ponto de vista conceitual e administrativo ao documento secreto, como afirma Jardim (1999b), os responsáveis pelos arquivos eclesiásticos também não deixam claro como atribuem tais classificações aos seus documentos. Apesar das disposições legais possuírem como dispositivo funcional as Comissões de acesso aos documentos, no caso dos arquivos eclesiásticos não é evidenciada tal conduta.

O CDC de 1983 esclarece quais são os documentos considerados secretos, evitando, desta forma, uma classificação indiscriminada de documentos com o teor secreto. Durante a pesquisa de campo, no entanto, nenhum entrevistado mencionou o Código de Direito Canônico como parâmetro para tal classificação, o que pode levar ao fato de muitos documentos serem considerados secretos pela inexistência de critérios claros de classificação.

Quatro entrevistados informaram que os documentos secretos já são criados com este teor, e assim são classificados pelos produtores. Em geral, esta classificação serve para localizar o documento de forma rápida e ainda para selecionar quais documentos podem ser liberados à pesquisa. Um entrevistado informou que a classificação secreta é dada aos documentos para preservar a Ordem. Outros dois não souberam dizer como identificar um documento secreto: acredita-se que isso ocorra em função de que em um arquivo os documentos não estão organizados e no outro arquivo os documentos secretos não ficam abrigados junto ao acervo e sim no setor jurídico da instituição. Para outro vale o bom senso, o que demonstra que não há previamente uma classificação para a identificação do documento secreto; esta identificação é realizada no momento da busca à informação por parte dos pesquisadores.

À exceção de um entrevistado, todos responderam desconhecer a disposição normativa carta circular sobre "A função pastoral dos arquivos" - da Santa Sé para o acesso aos documentos considerados como de interesse público e social pela legislação civil. Também desconhecem a 
existência da Comissão Pontifícia e os documentos por ela emanados para conservar e disseminar o patrimônio histórico-artístico da Igreja.

É compreensível que os entrevistados não conheçam o acordo internacional celebrado entre a Igreja Católica e o governo brasileiro no final do ano de 2008 sobre as suas responsabilidades a serviço da sociedade brasileira, pois este acordo ainda não entrou em vigor. Por outro lado, é indispensável que responsáveis por arquivos se interem da legislação arquivística vigente e delas se utilizem para melhorar a situação dos seus acervos, inclusive a partir dos acordos assinados pela Santa Sé com o governo.

Sobre o posicionamento dos sete entrevistados acerca de normas emanadas pela Igreja no Brasil para os arquivos eclesiásticos, um entrevistado respondeu conhecer as normas, mas não lembrava o título; outro deles respondeu não ser de responsabilidade da Igreja Católica no Brasil criá-las; os demais informaram não conhecer tais normas. Como efetivamente não existem normas da Igreja Católica do Brasil para os documentos eclesiásticos de maneira geral, ficou evidenciado que a maioria dos entrevistados, à exceção de um, tem conhecimento dessa lacuna.

Deve-se destacar a resposta de um entrevistado, que informou não ser de responsabilidade da Igreja no Brasil criar tais normas. Entretanto, os documentos emanados pela Santa Sé a partir das comissões pontifícias orientam de maneira geral que é necessário a formulação de programas específicos de ação, tendentes à conservação e à valorização do patrimônio arquivístico das Igrejas particulares. A Comissão Pontifícia para os Bens Culturais da Igreja (1997) ainda afirma ser de responsabilidade de cada uma das entidades eclesiásticas dos diversos países, devido à viva e crescente atenção dada aos bens culturais eclesiásticos, o material documentário ali recolhido. Sugere também a instituição de arquivos históricos, a tutela e conservação do arquivo secreto, o emprego de pessoal qualificado, a circulação de informações entre os diversos arquivos, além da participação em associações arquivísticas nacionais e internacionais, e a promoção da comunicabilidade do material recolhido para a consulta pública. Além disso, a Comissão sugere a instituição de comissões compostas pelos responsáveis dos arquivos e por especialistas da área arquivística.

Averiguou-se também que nenhum dos sete arquivos possui normas explícitas para acesso aos documentos secretos, nem quanto aos prazos de prescrição do sigilo. Na prática, demonstra-se que o acesso aos documentos secretos funciona dentro de uma concepção de restrição e controle do responsável, cuja liberação para a pesquisa ocorre em função do tema ou grau de vinculação acadêmica do pesquisador. Assim, a maioria dos entrevistados estabelece como instrumento de controle do acesso à informação secreta a autorização do próprio responsável ou o "bom senso", como um deles mencionou - já que não possuem normas em que se apoiar. Segundo Borges et. al. (2009), a ausência de uma política explícita acarreta em variação no aten- 
dimento, de acordo com o humor do atendente, com a aparência do usuário ou qualquer outro critério não condizente com a responsabilidade e função social de um arquivo histórico.

Assim, cada uma das instituições entrevistadas, de acordo com as suas especificidades, justificou o porquê da política de restrição à sua documentação, seja em razão do tema ou, ainda, em função da titulação acadêmica do pesquisador. Mas não há registro para as razões da restrição por parte do responsável pelo arquivo. Por outro lado, destaca-se que três dos sete arquivos apontaram interesse em criar tais normas; assim, demonstra-se que, embora longe da unanimidade, existe uma compreensão de que os arquivos históricos preservam documentos não como um fim em si mesmo, mas para tornar a informação que abrigam acessível em longo prazo. Além de que, os usuários têm o direito de conhecer as regras que regem o acesso e uso dos documentos e dos serviços do arquivo (SILVA, 2008). Como afirma Jardim (1999b), a existência de normas em um arquivo é referência básica à definição de políticas de informação e transparência nas ações das instituições ao qual o arquivo está ligado.

Existem semelhantes formas e condições de acesso pelo usuário, sendo unânime a necessidade de aviso prévio ao responsável, seja por agendamento telefônico ou carta de apresentação, elucidando o que se pretende com a pesquisa. Os documentos a serem consultados devem ser essencialmente históricos, pois, do contrário, a liberação não é permitida. A forma de atendimento é sempre presencial.

Quando o pesquisador não encontra ou não é liberado o acesso a determinadas informações - seja por razão do tema impróprio ou até quando o mesmo não possui titulação acadêmica exigida, a exemplo de estudantes de ensino médio ou de graduação -, ou ainda quando a informação recuperada não é satisfatória, este é orientado a procurar outros locais (arquivos, institutos, museus e outros). No geral, observa-se, portanto, que já há uma política de acesso e uso aos documentos, mesmo que seja de forma tácita. É necessário, porém, sistematizá-la por meio de disposições normativas que visem a tornar as práticas explícitas e claras para o pesquisador, mencionando os documentos secretos.

A existência de uma política de acesso e uso explícita, ou seja, escrita e divulgada que envolva os arquivos eclesiásticos - e seus acervos secretos - dará amparo legal e transparência aos arquivos, na medida em que estiver respaldada pela legislação em vigor e pelas normas da instituição à qual o arquivo está vinculado, cabendo ao pesquisador acatá-la.

Apenas dois dos sete arquivos estudados possuem instrumentos de pesquisa, sendo que em um deles o responsável não sabia informar qual o nome do instrumento utilizado: logo se observa para esta situação específica que ou o instrumento não atende às necessidades internas do arquivo, ou o responsável não o utiliza de fato. Em dois arquivos que não possuem instrumentos de pesquisa, há interesse em elaborar tais instrumentos em curto prazo, visando à busca imediata da informação. Isso confirma a visão de alguns arquivos em se transformarem de meros depositá- 
rios de documentos para centros de informação com novas utilidades para a sua instituição e a sociedade. Como afirma Santos (2005), a existência de instrumentos de pesquisa em arquivos históricos facilita o conhecimento dos fundos documentais mais pesquisados. Os instrumentos de pesquisa também tornam as atividades do arquivo mais dinâmicas, auxiliam na confecção de outros instrumentos de pesquisa que visam a identificar grupos ou séries específicas. Observou-se também que, no arquivo em que os documentos não foram tratados ou, ainda, nos arquivos onde inexistem instrumentos de pesquisa, não é sabido qual o tipo de documentação que seu acervo abriga.

Em todos os arquivos estudados, os responsáveis acreditam que não existe interesse em conservar a documentação eclesial, tanto por parte do governo quanto por parte das próprias instituições representadas pela Igreja Católica. Acreditam ainda que muitos responsáveis por arquivos eclesiásticos desconhecem a história dos próprios arquivos, e a sua funcionalidade. Demonstra-se, portanto, a partir destes fatos, a necessidade de organizar o acervo, e posteriormente construir arranjos e instrumentos de pesquisa visando a compreender quais as tipologias documentais existentes nos arquivos eclesiásticos.

\section{CONCLUSÃO}

Em linhas gerais, conclui-se que a classificação dos documentos secretos é realizada de forma aleatória nos arquivos eclesiásticos de Salvador. A falha se manifesta inicialmente na identificação do que é informação secreta por parte dos responsáveis, pois estes não demonstraram possuir domínio do significado de documentos secretos, já que acabaram entrando em contradição em suas afirmações. Esta falha poderia ser corrigida a partir da utilização da classificação adotada pelo Código de Direito Canônico de 1983, que define claramente a tipologia de documentos secretos, impedindo uma classificação indiscriminada, e também a partir da utilização da legislação civil que dispõe de vários dispositivos referentes à questão do acesso e sigilo dos documentos.

O estudo apurou que os critérios de classificação dos documentos de teor secreto são determinados, curiosamente, mais em função de "separar para encontrar rápido" do que em função do teor propriamente dito do documento. Assim, há certa confusão entre os objetivos de busca rápida da informação com os critérios de classificação para a documentação secreta. $O$ fato de não haver critérios explícitos de classificação para documentos secretos também implica que as instituições mantenedoras do arquivo não terão fundamentação para definir políticas de acesso específicas para essa documentação.

Fica evidente que os arquivos eclesiásticos brasileiros não podem sozinhos pôr em prática um plano orgânico de políticas arquivísticas eclesiásticas para todos os arquivos em questão, pois não possuem capacidade técnica nem financeira para a operacionalização da referida política. $A$ 
dificuldade da Igreja no Brasil para o desenvolvimento desta política parte da falta de recursos para as atividades que deverão ser estabelecidas a partir de um plano de trabalho, passando pela falta de mão-de-obra especializada para dar prosseguimento ao estabelecido nos objetivos, além de ausência, em muitos arquivos, de uma organização arquivística.

Nesse sentido, considerando a ausência de dispositivos normativos para os arquivos eclesiásticos, sugere-se primeiramente a elaboração de políticas de acesso aos documentos - que considerem a especificidade dos secretos - sempre respeitando a autonomia das instituições. A gestão da documentação, assim como a criação dos respectivos arranjos e instrumentos de pesquisa também ajudariam a compreender qual o papel do arquivo para a sua instituição e para a sociedade.

Ao mesmo tempo, enfatiza-se a necessidade de elaborar um projeto de políticas arquivísticas para os documentos eclesiásticos que englobe documentos administrativos, históricos e secretos. Tal projeto poderia ser conduzido pela Arquidiocese da cidade, juntamente com os responsáveis por arquivos de ordens religiosas, já que se trata de instituições semi-independentes. Salvador, cidade que mantém vasto acervo eclesiástico, poderia sediar um projeto-piloto, envolvendo todos os atores necessários à empreitada: além da Arquidiocese e ordens citadas, o próprio Instituto de Ciência da Informação da Universidade Federal da Bahia, que mantém o curso superior em Arquivologia, as associações de classe e os governos dos três níveis.

Os arquivos eclesiásticos possuem fundos documentais que representam quase um terço do total de todos os arquivos brasileiros e são constituídos, na sua maioria, por arquivos históricos. Entretanto, a guarda e o acesso aos documentos se dão através da determinação das instituições mantenedoras dos arquivos. Essa guarda e acesso deveriam se basear nas legislações canônica e civil, observando-se nesta última as indicações quanto aos prazos de prescrição para documentos sigilosos. No entanto, evidencia-se que não há uma preocupação por parte dos responsáveis em garantir o direito de acesso aos documentos identificados como de interesse público e social, caracterizados pela Lei $n^{\circ} 8.159$ como parte da memória nacional. Ou seja, o direito à informação contida nos documentos de arquivos de entidades religiosas não está sendo respeitado.

Para Honório e Damasceno (2006?), o direito à informação deixa de ser apenas um direito democrático e passa a se caracterizar também como um direito social e político, que deve ser garantido através de políticas públicas exercidas pelos arquivos no cumprimento de suas funções, pois é respaldado na forma da lei. Portanto, o direito à informação em arquivos eclesiásticos requer avanço da discussão sobre o acesso à informação de interesse público, refletindo-se em leis e dispositivos que visem a liberar o acesso aos documentos, ainda que com restrições e prazos prescricionais. Por ora, os arquivos eclesiásticos parecem ficar à parte, como que alheios às mu- 
danças sociais e ao próprio apelo das Comissões Pontifícias, que têm chamado a atenção dos responsáveis para o valor cultural e de fonte de informação histórica dos arquivos eclesiásticos.

\section{REFERÊNCIAS}

ABIB, Jamil Nassif. Arquivos eclesiásticos. In: Mesa Redonda Nacional de Arquivos, 1999, Rio de Janeiro. Anais eletrônicos... Rio de Janeiro: Arquivo Nacional, 1999. Disponível em:

http://www.arquivonacional.gov.br/. Acesso em: 25/11/2008.

ABREU, José Paulo. A Igreja e os seus arquivos: história e normas, até 1983. In: ROSA, Maria Lourdes; FONTES, Paulo F. O. (Coords.). Arquivística e arquivos religiosos: contributos para uma reflexão. Lisboa: Centro de Estudos de História Religiosa, 2000. p. 27-162.

ARQUIDIOCESE DE SALVADOR. Congregações. 2002. Disponível em: http://www.arquidiocesesalvador.org.br/congregaco es_3.htm. Acesso em 27/3/2009.

BORGES, Jussara; SILVA, Ana A. G.; ALVES, Márcia M.; CRUZ, Odeilma S.; SILVA, Patrícia M. Políticas de acesso e uso da informação nos arquivos eclesiásticos de Salvador. Arquivistica.net., 2009. [No prelo].

BRASIL. Constituição (1988). Constituição da República Federativa do Brasil. Brasília: Senado Federal, 1988.

BRASIL. Acordo entre a República Federativa do Brasil e a Santa Sé relativa ao estatuto jurídico da Igreja Católica no Brasil. Brasília: Ministério das Relações Exteriores, 2008. Disponível em: http://www2.mre .gov.br/dai/ b_santa_04.htm. Acesso em 21/4/2009.

BRASIL. Lei $n^{\circ} 8.159$, de 08 de janeiro de 1991. Dispõe sobre a política nacional de arquivos públicos e privados e dá outras providências. Disponível em: <http://www.

CONARQ.arquivonacional.gov.br/cgi/cgilua.exe/sys/startigohtm?infoid=100\& sid=52. Acesso em: $13 / 5 / 2008$.

BRASIL. Lei $n^{\circ} 11.111$, de 05 maio de 2005. Regulamenta a parte final do disposto no inciso XXXIII do caput do artigo $5^{\circ}$ da Constituição Federal e dá outras providências. Disponível em: http://www.planalto.gov.br/ccivil_03/_Ato2004-2006/2005/Lei/L11111.htm. Acesso em: 15/4/2009.

BRASIL. Decreto $n^{\circ} 119-A$, de 7 de janeiro de 1890. Prohibe a intervenção da autoridade federal e dos Estados federados em materia religiosa, consagra a plena liberdade de cultos, extingue 0 padroado e estabelece outras providencias. Disponível em: https://www.planalto.gov.br/ccivil_03/ decreto/1851-1899/d119-a.htm. Acesso em 27/3/2009.

BRASIL. Decreto $n^{\circ} 4.073$, de 03 de janeiro de 2002a. Regulamenta a Lei no 8.159, de 8 de janeiro de 1991, que dispõe sobre a política nacional de arquivos públicos e privados.

BRASIL. Decreto $n^{\circ} 4.553$, de 27 de dezembro de 2002b. Dispõe sobre a salvaguarda de dados, informações, documentos e materiais sigilosos de interesse da segurança da sociedade e do Estado, no âmbito da Administração Pública Federal, e dá outras providências.

BRASIL. Decreto $n^{\circ} 5.301$, de 9 de dezembro de 2004. Regulamenta o disposto na Medida Provisória $n^{\circ} 228$, de 9 de dezembro de 2004, que dispõe sobre a ressalva prevista na parte final do disposto no inciso XXXIII do artigo 5ํ da Constituição, e dá outras providências. 
BRASIL. Projeto de lei. 2009. In: Fórum Internacional de Direitos às Informações Públicas. Disponível: http://www.informacaopublica.org.br/files/PL-

REG\%20ACESSO\%20INFORMA\%C3\%87\%C3\%83O_L4_mar\%C3\%A702009.pdf. Acesso em: $22 / 4 / 2009$.

COMISSÃO PONTIFÍCIA PARA OS BENS CULTURAIS DA IGREJA. A função pastoral dos arquivos eclesiásticos. Roma, 02 de Fevereiro de 1997. Disponível em: <http://www.jesus.2000. years.de/roman_curia/pontifical_commissions/pcchc/documents/rc_com_pcchc_19970202_archivi ecclesiastici_it. html>. Acesso em: 29/3/2009.

COMISSÃO PONTIFÍCIA PARA OS BENS CULTURAIS DA IGREJA. Perfil. [2008?]. Disponível em: http://www.vatican.va/roman_curia/pontifical_commissions/pcchc/ documents/rc_com_pcchc_pro_20051996_sp.html. Acesso em: 29/3/2009.

COSTA, Célia Maria Leite. Acesso à informação nos arquivos brasileiros: retomando a questão. Estudos Históricos, Rio de Janeiro, n. 32, 2003, p. 1-2.

COSTA, Célia. Intimidade versus interesse público. Estudos Históricos, Rio de Janeiro, vol. 11, n. 21, 1998, p. 1-13.

DOMINUS VOBISCUM: do latim significa "o senhor esteja convosco". [2007?]. Disponível em: http://blog.cancaonova.com/dominusvobiscum/2007/11/07/o-arquivo-secreto-do-vaticano/. Acesso em: $25 / 11 / 2008$

FONSECA, Maria Odila. Direito à informação e arquivos municipais no Brasil. Buscalegis. 1997. Disponível em: http://www.buscalegis.ufsc.br/

revistas/index.php/buscalegis/article/view/16101/15665. Acesso em: 26/6/2009.

FONSECA, Maria Odila. Informação e direitos humanos: acesso às informações arquivísticas. Revista Ciência da Informação, Brasília, v. 28, n. 2, p. 146-154, set./dez. 1999.

FUNDAÇÃO HISTÓRICA TAVERA. Los archivos de América Latina. Madri: Fundación Mapfre Tavera, 2000.

GALÁN, Lola; MORA, Sérgio. Os papéis do Vaticano. In: Folha Online: El País Semanal, 2003. Disponível em: http://www1.folha.uol.com.br/folha/sinapse/ ult1063u700.shtml. Acesso em 27/3/2009.

HAYES, P. J. Ecclesiastical archives. In: CATHOLIC Encyclopedia. [2008?] Disponível em: <http://www.newadvent.org/cathen/01696a.htm>. Acesso em: 17/01/2009.

HONÓRIO, Cristiane da Cruz; DAMASCENO, Elizabeth Abreu. O direito à informação e os métodos de divulgação de arquivos e seus acervos. [2006?]. Disponível em: http://www.aargs.com.br/cna/anais/cristiane_honorio2.pdf. Acesso em: 29/6/2009.

IGREJA CATÓLICA. Código de Direito Canônico. Promulgado [pelo] Papa João Paulo II. Lisboa: Conferência Episcopal Portuguesa, 1983. Disponível em:

<http://www.vatican.va/archive/ESL0020/_INDEX.HTM>. Acesso em: 13/5/2008.

JARDIM, José Maria. O acesso à informação arquivística no Brasil: problemas de acessibilidade e disseminação. In: Mesa Redonda Nacional de Arquivos, 1999, Rio de Janeiro. Anais eletrônicos... Rio de Janeiro: Arquivo Nacional, 1999a. Disponível em: http://www.arquivonacional.gov.br/. Acesso em: 10/10/2007.

JARDIM, José Maria. Transparência e opacidade do Estado no Brasil: usos e desusos da informação governamental. Niterói: EdUFF, 1999b. Disponível em:

http://www.uff.br/ppgci/ppgci_livros.htm. Acesso em: 09/4/2009. 
RECONDO, Felipe. Projeto reduz prazo de sigilo de documentos. Jornal do Brasil, 2008.

Disponível em: http://www.estado.com.br/editorias/2008/11/29/pol-1.93.11.20081129.1.1.xml. Acesso em: 30/11/2008.

RODRIGUES, Georgete M.; HOTT, Daniela F. M. Acesso aos documentos sigilosos no Brasil: instrumentos normativos formais e informais nos arquivos públicos brasileiros. In: VII Congreso de Archivologia del Mercosur, 2007, Viña del Mar. VII Congreso de Archivologia del Mercosur. Viña del Mar: Associación de Archiveros de Chile / Archivo Historico e Patrimonial, 2007. Disponível em: http://www.asocarchi.cl/DOCS/ 70. PDF. Acesso em: 25/6/2009.

SANTOS, Cristian José Oliveira. Os arquivos das primeiras prelazias e dioceses brasileiras no contexto da legislação e práticas arquivísticas da Igreja Católica. Dissertação de Mestrado em Ciência da Informação - Faculdade de Economia, Administração, Contabilidade e Ciência da Informação e Documentação, Universidade de Brasília, 2005.

SILVA, Patrícia M. Política de acesso e uso da informação em arquivos eclesiásticos católicos de Salvador. 2008. 47 f. Trabalho de Conclusão de Curso (Graduação) - Instituto de Ciência da Informação, UFBA, Salvador, 2008.

VIANNA, Helena Besserman. Segredo e poder. Pulsional Revista de Psicanálise. São Paulo, n. 137, 1999, p. 90-96. Disponível em: http://www.editoraescuta.com.br/pulsional/137_09.pdf. Acesso em: 01/4/2009.

\title{
Title
}

Ecclesiastical secret archives in Salvador, Brazil

\begin{abstract}
This study deals with the criteria employed in the identification of religious orders' secret archives from the Archdiocese of Salvador, Bahia, Brazil. The paper considers the historical relationship between the Catholic Church and the civil authorities in an effort to understand the rationale behind the strategy employed in depositing "public and social interest" documents, as defined by federal legislation. The paper examines the existing norms and definitions that can be identified in both civil and canonic legislation related to closed or "secret" archives. Additionally, the questions of access and information confidentiality, within the context of information access rights are discussed. The sample of male and female monastic orders, with whom a semi structure interview was conducted, was selected from Salvador's Archdiocese website. The results indicate that no explicit criteria exist for the classification of secret documents accumulated in the ecclesiastic archives and that the responsible authorities do not have a consistent idea concerning the significance of secret documents, due to some contradictions observed.
\end{abstract}

\section{Keywords}

Ecclesiastic archives. Secret Archives. Access Rights. 


\section{Título}

Archivos secretos eclesiásticos en Salvador de Bahía

\section{Resumen}

La presente investigación estudia los criterios que emplean los archivos de índole religiosa para identificar el teor secreto de sus documentos. Se tomó en consideración las relaciones históricas entre la Iglesia católica y el poder civil para comprender las razones por las cuales muchos de los documentos existentes en los archivos eclesiásticos brasileños se identifican por su interés público y social, según la legislación nacional. Este estudio asimismo pone de manifiesto la normativa que resulta de la legislación civil y canónica sobre los archivos secretos. Enseña aún una pequeña discusión acerca del acceso y del sigilo de la información. En cuanto a los procedimientos metodológicos se utilizó el sitio electrónico de la Arquidiócesis de Salvador, en donde se seleccionó los órdenes religiosos masculinos y femeninos. Luego, se aplicó una entrevista semiestructurada, teniendo en cuenta recoger datos para los resultados empíricos de la investigación. Finalmente, se concluye que no hubo criterios específicos para clasificar los documentos considerados secretos en los archivos eclesiásticos católicos de Salvador de Bahia, hecho que llevó a la utilización de criterios aleatorios. Como consecuencia, quedó evidente la falta de dominio acerca del significado de documentos secretos por parte de los responsables de los archivos, ante sus afirmaciones contradictorias.

\section{Palabras Clave}

Archivos eclesiásticos. Archivos secretos. Derecho a la información.

Recebido em: 18.08 .2009

Aceito em: 09.03.2010 